\title{
Autoatención de los padecimientos y algunos imaginarios antropológicos
}

\author{
EDUARDO L. MENÉNDEZ
}

as enfermedades, como es obvio, operan en toda sociedad conocida, por lo tanto, todas las sociedades han generado formas específicas de atención y prevención para abatir, reducir o convivir con los padecimientos que reconocen como tales. En las sociedades latinoamericanas actuales, incluida gran parte de los pueblos originarios, coexisten formas de atención a las enfermedades en las que la biomedicina no sólo constituye la forma hegemónica, sino la que está en constante proceso de expansión. ${ }^{1}$

Esta afirmación implica cuestionar la mirada antropológica dominante en nuestros países hasta hace pocos años pues, salvo algunas excepciones, la mayoría de los estudios antropológicos sobre los procesos de salud/enfermedad/atención-prevención (s/e/a-p) desarrollados en las comunidades indígenas latinoamericanas se reducía a describir las enfermedades y los curadores tradicionales, y excluía de sus etnografías a las instituciones y saberes biomédicos. Esos textos no incluían la forma de atención de los padecimientos que se estaba convirtiendo en hegemónica y pasaba a ser parte de los usos y costumbres cotidianos de la mayoría de los pueblos originarios, por lo menos en México.

Self-attention of Sufferings and Some Anthropological Imagineries

EduARdo L. MenÉndeZ Centro de Investigaciones y Estudios Superiores en Antropología SocialCiudad de México, México emenendez1@yahoo.com.mx

Desacatos 58, septiembre-diciembre 2018, pp. 104-113
Una serie de estudios ha puesto en evidencia las transacciones entre las formas de atención de los padecimientos, en las que los sujetos y microgrupos son los principales actores sociales de este proceso interactivo. Si bien pueden intervenir varios tipos de curadores, dicho proceso es llevado a cabo básicamente por la población como parte normalizada de su vida cotidiana. No obstante, gran parte del trabajo antropológico, sobre todo referido a determinados procesos de s/e/a-p, se ha concentrado en los curadores tradicionales, ya sean chamanes, herbolarios o parteras, y ha dejado en un lugar secundario a la

1 Las principales formas de atención que operan en nuestros países son: a) biomédicas; b) medicina tradicional; c) medicinas alternativas o paralelas; d) devenidas de tradiciones académicas no occidentales, y e) autoatención. 
población, de manera que su etnografía no registra los procesos interactivos generados en torno a los padecimientos por los sujetos y microgrupos, sino sólo los que operan los curadores tradicionales. Esto no demerita la calidad de muchos de estos trabajos, sólo señala sus limitaciones y ausencias.

Éstas y otras tendencias han generado una antropología de los procesos de s/e/a-p en las comunidades indígenas y no indígenas, que ha tendido a ignorar tanto el creciente papel directo e indirecto de la biomedicina, como algunos de los principales procesos de producción y reproducción biocultural, por ejemplo, el que se desarrolla por medio de las formas de autoatención de los padecimientos.

Comprendemos los objetivos que causaron esa orientación, que en parte tienen que ver con el énfasis puesto en la "diferencia” y el empoderamiento indígena como mecanismos de su rehabilitación social y cultural, así como con la búsqueda de vinculación de lo tradicional actual con las cosmologías ancestrales, como evidencia de una continuidad cultural que legitime las demandas de las comunidades nativas. Sin embargo, esta orientación se ha alejado cada vez más de lo que acontece en realidad en las comunidades en términos de los procesos de s/e/a-p. Esta tendencia expresa sobre todo la "interpretación" de una parte de los antropólogos o los deseos de una parte de los líderes e intelectuales indianistas, pero no lo que ocurre en la vida cotidiana de los sectores sociales subalternos, incluidos los pueblos indígenas.

\section{Autotaención como estructura y proceso}

Si los antropólogos no sólo preguntaran en las comunidades por el susto, el empacho o el mal de ojo, y dejaran de entrevistar sólo a parteras, herbolarios o chamanes, e interrogaran también a la población sobre el cáncer, el VIH-sida, la diabetes mellitus y la atención biomédica, se hubieran enterado de que por lo menos una parte de la población nativa —incluidos los curadores tradicionales - reconoce que dichas enfermedades afectan a una porción de la población y que además, para enfrentarlas, recurre a sus formas tradicionales de atención y también a la atención biomédica, o como mínimo, a los productos biomédicos. Tal vez esto los llevaría a reflexionar sobre algunos de sus supuestos teóricos, sobre todo ideológicos, por ejemplo, el de las incompatibilidades que, según ellos, existen entre las concepciones —cosmovisiones - tradicionales de los padecimientos y su sanación, y las concepciones biomédicas de las enfermedades y su curación, y tratarían de entender por qué los sujetos y microgrupos de los pueblos originarios no parecen tener problemas en utilizar — con frecuencia y de manera simultánea- la diversidad de formas de atención de los padecimientos que, según estas tendencias, corresponderían a cosmovisiones diferentes. Justamente, la autoatención sintetiza, o por lo menos articula, las diferentes formas de atención en apariencia incompatibles.

Es decir, lo observado en la vida cotidiana de los sujetos y microgrupos contrasta con las propuestas de incompatibilidad no sólo de antropólogos sociales, sino de intelectuales indianistas, y en menor medida, de sus líderes políticos, sobre todo cuando éstos tienen una cuota de poder y son parte del gobierno, incluidos los progresistas y proindígenas. Por ejemplo, durante la gestión presidencial de Evo Morales en Bolivia, se creó un Subministerio de Medicina Tradicional y Salud Intercultural con un presupuesto mínimo, mientras casi toda la inversión en salud se destina a la biomedicina, en especial a ciertos programas biomédicos que intentan reducir las altas tasas de muertes evitables que inciden en la población en general y en la indígena en particular, ante las cuales la medicina tradicional ha mostrado poca eficacia. Esto no supone una exclusión y menos una desvaloración de la medicina tradicional por parte del gobierno boliviano, pero encarna una decisión política que impulsa y financia el tipo de 
medicina más eficaz para reducir los problemas más graves e inmediatos, al mismo tiempo que reconoce los usos simultáneos — no la incompatibilidad- de la biomedicina y la medicina tradicional por parte de la población indígena y no indígena.

Lo señalado no niega los usos y eficacias específicos de la medicina ni de los curadores tradicionales, cuyo papel principal es la comprensión y explicación de los padecimientos, para que las comunidades y sujetos convivan en términos interpretativos y prácticos con ellos, y generen eficacias simbólicas y no simbólicas para atender las enfermedades que reconocen. Además, aclaro, no se propone tampoco que sólo la biomedicina reduce las tasas de mortalidad generales y de los pueblos originarios en particular. Lo que se cuestiona es la manera en que antropólogos e intelectuales indianistas buscan y usan las cosmovisiones que fundamentarían las medicinas tradicionales como si fueran realidades esenciales, al proponer no sólo incompatibilidades sino una suerte de quietismo ahistórico que poco tiene que ver con los procesos socioculturales, económicos y políticos actuales.

Ahora bien, lo que me interesa señalar en este texto - pues tiene que ver con los trabajos presentados en este número de Desacatos - es el papel de la autoatención en los procesos de s/e/a-p y su potencialidad social, ideológica, y en menor medida, política (Menéndez, 1983). La autoatención no sólo tiene un papel decisivo en la síntesis, articulación o mezcla que los sujetos y microgrupos generan entre las formas de atención que operan en su vida cotidiana, sino que constituye la forma de atención de los padecimientos y enfermedades más frecuente y constante (Menéndez, 1982a; 1984; 1992; 2009).

La autoatención refiere a los saberes, es decir, a las representaciones y prácticas sociales que los sujetos y microgrupos utilizan para diagnosticar, explicar, atender, controlar, aliviar, soportar, curar, solucionar o prevenir los procesos que afectan su salud en términos reales o imaginarios, sin la intervención central, directa e intencional de curadores profesionales, aun cuando éstos pueden ser la referencia de la actividad de autoatención. Así, la autoatención implica decidir la autoprescripción y el uso de tratamientos de manera total o relativamente autónoma, incluso si ya han sido indicados por curadores de las distintas formas de atención. Estas autoprescripciones, en función de cada padecimiento y de las condiciones socioeconómicas y situación de los sujetos y microgrupos, conducen a que una parte del proceso de prescripción y uso de terapéuticas adquiera autonomía, por lo menos en términos relativos.

La autoatención puede pensarse en dos niveles. El primero abarca todas las formas de autoatención que se requieren para asegurar la reproducción biosocial de los sujetos y microgrupos, en especial del grupo doméstico. Estas formas se utilizan a partir de los objetivos y normas establecidos por la cultura del grupo. Desde esta perspectiva, podemos incluir las actividades de preparación, distribución y consumo de alimentos; el aseo del cuerpo, el hogar y el medio ambiente inmediato; la obtención y uso del agua, la eliminación de excrementos y un largo etcétera que contempla, por ejemplo, hacer frente a la muerte, los muertos y los deudos en los términos prescriptos por cada cultura.

El segundo nivel se refiere a los procesos de s/e/a-p, sobre los que desarrollaremos nuestro análisis, sin dejar de apuntar que es difícil establecer un corte claro entre los dos niveles. En ambos, aun cuando la autoatención aparezca de manera fenoménica en individuos, siempre alude a microgrupos y grupos, en particular a los que más inciden en los procesos de reproducción biosocial, que incluyen al grupo familiar en un lugar protagónico (Litman, 1974), pero también al grupo de trabajo, de escolares, amigos, etcétera. ${ }^{2}$

2

Mientras la autoatención se refiere al microgrupo y la relación del sujeto consigo mismo, el autocuidado propuesto por la biomedicina se enfoca en el individuo. 
El proceso de autoatención de los padecimientos se fundamenta en varios hechos, sobre todo en dos. Por una parte, en la gran frecuencia, recurrencia y continuidad de padecimientos, daños o problemas de salud que afectan cada día a los sujetos pertenecientes a los grupos primarios desde que nacen hasta que mueren. Los padecimientos son algunos de los hechos más constantes de nuestra vida cotidiana, ya sea en su forma aguda o crónica. Por esto, los procesos de s/e/a-p constituyen uno de los campos — para algunos el principal - en los que las sociedades crean el mayor número de representaciones y prácticas sociales. Además, en el caso de las discapacidades y las enfermedades crónicas o cronificadas, como el VIHsida, el padecimiento pasa, cada vez más, a formar parte de la identidad de los sujetos y a veces de los grupos sociales (Menéndez, 1994).

$\mathrm{Al}$ respecto, necesitamos asumir que en todas las sociedades conocidas, la enfermedad, y no la salud, ha constituido el estado "normal" de los sujetos. Esto se ha reforzado en las sociedades actuales, dado el notable incremento de la esperanza de vida. Por ejemplo, en los países europeos más desarrollados la esperanza de vida a mediados del siglo XIX era de 30 a 40 años $^{3}$ y ahora está cerca de los 80 (McKeown, 1976; Pinker, 2012). La prolongación de la esperanza de vida se basa en varios procesos, en especial en la reducción de la mortalidad por enfermedades que hasta hace pocos años eran letales para la mayoría de la población.

Entonces, cuando nos enteramos de que 30\% de la población mundial tiene insomnio; $12 \%$ padece migraña; y, según la Organización Mundial de la Salud, en 2050 la mitad de la población tendrá algún tipo de cáncer, eso no sólo implica que alguna enfermedad es parte de nuestro estado normal de vida, sino que los sujetos y sus microgrupos necesitan desarrollar comportamientos —en su mayoría, de autoatención - para convivir con padecimientos que ya son parte de su identidad y subjetividad en la trayectoria de su vida.
En función de esta presencia cotidiana, el segundo hecho refiere a que los sujetos y sus microgrupos de todas las clases y sectores sociales necesitan realizar acciones inmediatas y permanentes para solucionar de manera radical o provisional los problemas de salud que los aquejan o amenazan. Lo hacen desde la detección y durante todo el lapso que dure el padecer mediante la autoatención. Una serie de investigaciones ha puesto en evidencia que la demanda de consulta médica es reducida en relación con el número de episodios de enfermedad que ocurren en la población, dado que la mayoría son atendidos, o desatendidos, por los propios sujetos y microgrupos, sobre todo por el grupo familiar.

Dadas estas condiciones, la mayoría de los microgrupos, en particular el doméstico, necesita generar saberes para explicar, atender, contener y resolver las situaciones cotidianas de enfermedad, incluida la decisión de consultar a un curador profesional o no atenderse. Así, en toda sociedad, la autoatención constituye el primer nivel real de atención, prevención y comprensión.

La autoatención es una estructura permanente que los microgrupos generan en toda sociedad para atender sus padecimientos, que se caracteriza por un proceso constante de cambio, al igual que las otras formas de atención, incluida la denominada medicina tradicional (Boccara, 2017; Menéndez, 1994). La carrera del enfermo y la trayectoria de enfermedad tienen como punto de partida y llegada la autoatención. La autoatención es casi siempre la primera actividad que el sujeto y el microgrupo ejecutan respecto a los padeceres detectados. Esa actividad, en principio, no incluye ningún curador profesional, incluso si se consultan vecinos, compañeros de trabajo o amigos, porque no se desempeñan como

En México, en 1930, la esperanza de vida al nacer era de 36 años (Bustamante, 1946; Bustamante y Aldama, 1940; 1941). 
curadores profesionales. Además, la autoatención “acompaña” todo tratamiento propuesto por curadores profesionales en una trayectoria en la que la mayoría de los sujetos trata de autonomizar los tratamientos. Cabe señalar que algunos sujetos y microgrupos deciden no atender al menos una parte de sus padecimientos debido a causas diversas, lo que también es parte de la autoatención.

Toda consulta a curadores profesionales se hace desde los saberes y experiencias individuales y colectivos. Por ello, el sujeto y sus microgupos son los que están al tanto de toda la carrera del enfermo, mientras la mayoría de los curadores profesionales, que representan las otras formas de atención, permanece casi siempre ignorante al respecto, y sobre todo, de la articulación que los sujetos y sus microgrupos establecen entre las diferentes formas de atención, con el objetivo de hallar una solución a sus problemas de salud.

A partir de lo que acontece en la autoatención y en la evolución del padecimiento, así como en función de las condiciones socioeconómicas y culturales, incluidas las formas de atención a las que tienen acceso, el sujeto y su microgrupo deciden consultar o no a curadores profesionales de algunas de las formas de atención que reconocen y aceptan, a las que pueden acceder en términos económicos, socioculturales y geográficos.

La decisión de consultar a un curador profesional y algunas de las actividades que se realizan luego de la consulta también son parte del proceso de autoatención, en la medida en que se autonomicen y en función de que casi siempre habrá diferencias entre lo recomendado por el profesional y lo que el paciente y su microgrupo hagan. La autoatención no sólo es estructural, sino que siempre es un proceso en relación con otras formas de atención. Uno de los problemas metodológicos es la tendencia a reducir la autoatención a estructura y no verla como proceso, lo que limita o impide comprender el papel decisivo de la autoatención en la reproducción biosocial de los microgrupos y en el desarrollo de posibilidades contrahegemónicas.

Considerarla proceso posibilita observar una serie de hechos que, por ejemplo, cuestionan las interpretaciones médicas o ponen en evidencia los cambios constantes que operan en los saberes populares. La autoatención, por lo tanto, debe estudiarse como estructura y como proceso, no sólo por las razones señaladas, sino porque implica, desde la perspectiva de los sectores sociales subalternos, la acción más racional en términos socioculturales y de costobeneficio, no sólo económico, sino también del uso del tiempo.

La autoatención opera por medio de las relaciones que se establecen — por supuesto, entre sujetos y microgrupos - de manera directa e indirecta con las otras formas de atención, y trata de apropiarse de sus aspectos más accesibles, para convertirlos en partes de la autoatención. Esta apropiación se concentra en los saberes y productos más eficaces y de efectos más inmediatos, por lo cual la mayoría de las apropiaciones en la actualidad suceden respecto a los fármacos biomédicos.

Esto no sólo supone un proceso de retroalimentación permanente, sino de cambios. Sociólogos británicos plantearon desde la década de 1980 el surgimiento de un nuevo tipo de paciente, llamado "paciente bien informado", que no sólo se caracteriza por estar preocupado por la enfermedad que lo aqueja, sino por saber todo lo posible sobre ella. Así, cuando asiste al médico, además de que reconoce positivamente lo que éste le diagnostica y prescribe, discute la eficacia que el fármaco prescrito y la dosis recomendada pueden tener, dado que analiza sus efectos tanto en la bibliografía médica como en los mensajes en internet, pero sobre todo en su propio cuerpo; por lo tanto, el paciente reduce o aumenta la dosis en función de lo que le pasa como sujeto, sin acatar lo recomendado por el médico. No lo hace por oponerse o rechazar la prescripción médica ni por ignorancia respecto a 
la necesidad de aplicar y completar la dosis recomendada, sino justamente por un análisis de su experiencia de la enfermedad basado en el saber biomédico (Donovan y Blake, 1992).

Es decir, estamos ante un tipo de relación que hace evidente el desarrollo articulado de procesos de atención profesional y de autoatención, que contradice las nociones dominantes de atención biomédica y autoatención por la tendencia a pensar en la autoatención como algo negativo y sobre todo por concebir los modelos de atención de manera escindida, en lugar de ver su funcionamiento complementario en la vida cotidiana. Para esto, necesitamos observar la vida cotidiana desde la perspectiva de la población, no sólo de los curadores.

Tenemos que ver en la cotidianidad de la vida de los sujetos y microgrupos cómo permanecen, desaparecen y cambian las representaciones y prácticas sociales, incluso las "instituciones" referidas a los procesos de s/e/a-p, y cómo esos cambios se desarrollan a partir de los recursos de los sujetos y sus microgrupos, sintetizados en los procesos de autoatención.

\section{Lo bueno, lo malo y lo posible de la autoatención}

En términos específicos, lo más rescatable de la autoatención es la capacidad de los sujetos y microgrupos de intervenir con autonomía total o relativa en los padecimientos que los aquejan y hacerlo con determinado nivel de eficacia e inmediatez. Esto ha sido negado históricamente por la biomedicina, dado que subraya con frecuencia las consecuencias negativas de la autoatención, pensada en términos de automedicación con fármacos.

Es correcto reconocer las consecuencias negativas de la autoatención, así como que los sujetos y microgrupos generan padeceres, desde enfermedades mentales hasta violaciones sexuales, pasando por homicidios y suicidios cometidos por los miembros en el interior de los microgrupos, pero no por eso debemos pensar en la autoatención sólo en términos negativos, sino que necesitamos asumir que es parte de la estructura y función de los sujetos y los pequeños grupos, y que cumple funciones positivas además de que puede dar lugar, incluso de manera simultánea, a procesos y consecuencias negativos y positivos como parte de su desarrollo y funcionamiento.

La biomedicina ha subrayado de manera permanente ciertos aspectos negativos de la autoatención, pero desde fechas tempranas también ha reconocido aspectos positivos, como en el caso de la convalecencia, aunque no la considera parte de la autoatención. Por lo tanto, en la biomedicina y la profesión médica dominan visiones críticas y estigmatizantes de la automedicación, en gran medida debido a que los sujetos se han apropiado de uno de sus principales instrumentos curativos o paliativos identificado con los médicos, es decir, los medicamentos.

La biomedicina y el Sector Salud han desarrollado una mirada contradictoria - mejor dicho, dicotómica - de la autoatención, pues junto a la crítica proponen el autocuidado, los clubes de diabéticos y el papel del sujeto en el diagnóstico de sus propios problemas, siempre y cuando el ejercicio de medicación quede sólo en manos de los médicos. De ahí su ataque constante a la automedicación, a la que separa, o por lo menos no relaciona, con el autocuidado y los grupos de autoayuda. De esa manera, la biomedicina propicia una visión esquizoide de la autoatención, en la que ciertos comportamientos del sujeto, como automedirse la glucosa, correr por los parques o preparar soluciones de rehidratación oral, son considerados positivos, mientras automedicarse con fármacos se estigmatiza.

Es decir, la mirada médica fractura la estructura y función de los saberes de los sujetos y microgrupos, y los lleva a automedicarse ante todo padecimiento. Esto conduce de manera casi 
inevitable a que la biomedicina elabore propuestas y acciones de control y prohibición de la compra "libre" de determinados medicamentos para evitar la automedicación. Recordemos que esta actitud prohibicionista de la biomedicina respecto a la automedicación convive tanto con los mensajes biomédicos constantes que impulsan determinadas formas de autoatención, incluida la automedicación, como con la inducción directa e indirecta de la industria químico-farmacéutica a automedicarse.

La biomedicina ha visto y sigue viendo en la automedicación un fuerte competidor profesional, en lugar de asumirla como la forma de atención con la cual tendría que articularse de manera intencional, por ejemplo, al enseñar a la gente a autoatenderse y automedicarse bien. No sólo saber autoaplicarse insulina o palparse los senos para detectar nódulos posiblemente cancerosos, sino respecto a todo padecimiento. Tendría que enseñar a la gente a automedicarse bien, porque además casi todos los sujetos tienden a hacerlo y a apropiarse del saber médico y los otros saberes sanadores. Esa inevitabilidad tiene que ver con procesos muy diversos, que van desde los factores económicos, pasando por los estilos de vida, hasta el uso del tiempo.

El Sector Salud y los médicos, por lo menos en los países latinoamericanos, parten del supuesto de que la población se automedica, y en general, se automedica mal, lo que provoca problemas tanto individuales como colectivos. Con frecuencia se utiliza el ejemplo de los antibióticos, como evidencia de que el mal uso popular ha conducido a generar cada vez más resistencia biológica hacia ellos, pero se omite que la población aprendió gran parte del mal uso de los antibióticos de los propios médicos. Desde la década de 1950, reiteradas investigaciones realizadas en Estados Unidos señalan que los médicos, en especial los pediatras, recetan demasiados antibióticos a los niños que atienden. El último estudio que conocemos (Kronman, Zhou y Mangione, 2014) encuentra que los pediatras recetan dos veces más antibióticos de los que en realidad requieren los niños con infecciones de oído y garganta, y sostiene que más de 11 millones de recetas de antibióticos emitidas cada año para niños y adolescentes podrían ser innecesarias.

La biomedicina necesita establecer un corte esquizoide respecto de la automedicación con fármacos debido en gran medida a que los sujetos y grupos han aprendido de los médicos los reiterados malos usos. La historia farmacológica del saber médico, en cierta medida, es la historia de los fármacos recetados por médicos durante años, que luego de un periodo de aplicación resulta que son inoperantes, nocivos o que han generado resistencias. Por ejemplo, tomó 75 años llegar a saber que la fenacetina provoca nefropatías, 30 años para conocer que la amidopirina causa agranulocitosis y diez años para descubrir que la tetraciclina trastorna el desarrollo óseo. El destilbene, que se aplicó desde finales de la década de 1950 a mujeres embarazadas, se retiró del mercado 20 años después al descubrirse sus consecuencias cancerígenas y que alteraba seriamente el ciclo reproductivo.

Toda una serie de fármacos considerados hoy restringidos y con consecuencias negativas fueron recetados sin restricción durante muchos años. La población no decidió por sí misma usar antibióticos para diversos tipos de diarrea, lo aprendió de los médicos. En 1946, pocos años después de difundirse el uso de la penicilina, dos investigadores mexicanos concluían:

El éxito alcanzado en el tratamiento de determinadas infecciones bacterianas por aplicación de penicilina ha conducido a un empleo anárquico y desmedido de la droga. Este antibiótico ha sido empleado no sólo en cualquier afección con gérmenes, sino hasta en entidades clínicas que no tienen por causa microrganismos (González y Sandoval, 1946: 193). 
Lo mismo ocurrió con drogas recetadas contra el paludismo o en relación con problemas de salud mental en las décadas de 1950 y 1960. Lo preocupante es que esto sigue ocurriendo en la actualidad con consecuencias similares, como en el caso de la crisis de las drogas opiáceas recetadas por médicos en Estados Unidos, que se ha convertido en uno de los más graves problemas de salud pública en ese país.

Considero que no hay duda acerca de que la población utiliza mal los medicamentos, pero también pienso que una parte de la población los utiliza bien, aunque no lo sabemos "científicamente" porque eso no ha sido estudiado por el Sector Salud ni por la academia científica. No conozco investigaciones sobre Latinoamérica que estudien sujetos y grupos para observar tanto el mal uso como el uso correcto y eficaz de los medicamentos en términos de autoatención, pese a que determinadas experiencias demuestran que la población, incluida la de menor formación educacional, puede hacer uso correcto y eficaz de los medicamentos.

Por ejemplo, en la evaluación de los resultados de un proyecto de investigación/acción aplicado en una zona palúdica ecuatoriana en la que reside población amerindia, los investigadores compararon el autodiagnóstico - parte sustantiva de la autoatención- de las personas que habían tenido malaria con el diagnóstico profesional y encontraron una coincidencia de $80 \%$ de los casos, por lo que concluyeron que el autodiagnóstico tiene un buen valor predictivo. Este proyecto impulsó el autotratamiento contra la malaria basado en fármacos biomédicos, completado con plantas medicinales (Kroeger et al., 1991; Litman, 1974).

Por supuesto, contamos con estudios en diferentes países que reiteran, por ejemplo, que una parte de los enfermos crónicos no cumplen con sus tratamientos y que una parte de los padecimientos agudos son tratados de manera incorrecta. Pero también contamos con trabajos que analizan y demuestran la eficacia de los sueros de rehidratación oral utilizados por los grupos familiares para reducir la mortalidad infantil por diarreas (Populations Reports, 1981). Más aún, desde hace décadas se ha planteado que no sólo se ha simplificado el uso de muchos fármacos, sino que:

Con los rápidos progresos de la ciencia médica y el extraordinario interés de los descubrimientos que los acompañan, apenas se ha advertido que el control de los padecimientos más básicos de las poblaciones se ha convertido en un problema bastante sencillo [...]. El mayor cambio estriba en que ya no se necesita una tecnología superior ni extensos conocimientos (médicos) para brindar atención eficaz para la mayor parte de las enfermedades básicas. Pero se requieren cambios en los primeros eslabones de la cadena de referencia. Esto significa más responsabilidad a nivel familiar e individual, y más conocimiento de lo que se debe hacer y cómo hacerlo (Backett, 1978: 313-314).

Lo que señalaba Backett hace casi 40 años es aún más vigente en la actualidad. Por ello, y por las razones expuestas en este texto, considero - como he mencionado- que una de las tareas básicas del Sector Salud debería ser enseñar a los sujetos y microgrupos no sólo a prevenirse sino a autoatenderse, en especial, a automedicarse mejor.

Ahora bien, los procesos de autoatención, incluida la automedicación y los grupos de autoayuda, implican potenciales ejercicios de autonomía y decisiones propias de los sujetos y microgrupos (Aranda, 2010; Campiglia, 2017; Ortega y Palma, 2017). Estos procesos conllevan la existencia de sujetos activos, a veces agentes, que pueden operar con los recursos materiales y no materiales con los que cuentan. Los procesos de autoatención expresan el pragmatismo permanente de los sectores sociales subalternos y también su capacidad de apropiación y aprendizaje de los saberes que consideran eficaces y pueden servirles. Es decir, la autoatención 
no sólo puede ser eficaz para tratar padecimientos, sino que a partir de ello puede constituirse como un lugar de resistencia, de ejercicio de empoderamiento y a veces de contrahegemonía.

Al mismo tiempo, la autoatención es uno de los principales procesos por medio de los cuales la biomedicina y la industria químico-farmacéutica ejercen su hegemonía, mientras los sectores sociales subalternos generan estrategias de "aguante" para sobrevivir, a la vez que favorecen la hegemonía, no sólo biomédica, sino de los sectores sociales dominantes en términos económicos y políticos. Más aún, la autoatención puede ser apoyada de manera directa, pero sobre todo indirecta, por el Sector Salud, para que los propios sujetos y microgrupos se hagan cargo de sus padecimientos, y descargarse de esa responsabilidad social. Esto explicaría, al menos en parte, el hecho de que Estados Unidos haya sido y siga siendo el país que ha creado el mayor número y variedad de grupos de autoayuda, dado que entre de los paises más desarrollados es el que menos ha impulsado una cobertura de salud universal gratuita o parcialmente gratuita.

Pero esta condición - lo subrayo- sólo explica en parte, si es que lo explica, lo que ocurre en la sociedad estadounidense, por lo que necesitamos buscar propuestas más complejas e inclusivas, como las desarrolladas por Wuthnow (1996). Apunto a lo mismo respecto del interés de la industria químico-farmacéutica por impulsar la autoamedicación como uno de sus principales objetivos económicos, pues ese impulso implica una erosión constante del poder y saber biomédico.

Debemos admitir que la mayoría de los procesos que vivimos son complejos, contradictorios y ambivalentes, y que pese a ello gran parte de nuestras explicaciones suelen ser simplificadoras - como ocurre con el concepto de biopoder foucaultianoy lo que es más grave, pensamos en la realidad en términos unilineales, manifiestos y arrelacionales. Así, los procesos de autoatención pueden constituir para algunos la principal expresión de la sumisión de los sujetos y microgrupos subalternos respecto de los sectores dominantes y hegemónicos, mientras para otros es una de las principales expresiones de su autonomía, agencia y empoderamiento.

En lo personal, me interesan los procesos de autoantención por varias razones, en especial porque son una de las principales estrategias de supervivencia de los sectores sociales subalternos y porque presentan posibilidades de autonomía, empoderamiento y contrahegemonía planteados en términos de autogestión política (Menéndez, 1983), pero, reitero, necesitamos observar esas posibilidades en las situaciones concretas sin caer en los esencialismos ideológicos que hoy dominan los discursos teoricistas en Latinoamérica. D

\section{Bibliografía}

Aranda, Patricia, 2010, Los motivos de la "desidia". Estudio sociocultural de los saberes legos sobre el papanicolau y el cáncer cérvicouterino, El Colegio de Sonora, Hermosillo.

Backett, Maurice, 1978, "La cuestión de la política de salud: los cambios más importantes en nuestra actividad frente a los problemas de salud", en Boletín de la Oficina Sanitaria Panamericana, vol. 84, núm. 4, pp. 313-323.

Boccara, Michel, 2017, "Tradición, improvisación y modernidad en el chamanismo maya yucateco: el arte suhuy de Juan Cob, $h$-men de Yaxcabá”, en Salud Colectiva, vol. 13, núm. 3, pp. 429-442.

Bustamante, Miguel E., 1946, "Vida media en México”, en Gaceta Médica, t. 76, núm. 3-4, pp. 177-191.

Bustamante, Miguel E. y Antonio C. Aldama, 1940, “Tablas de vida de los habitantes de los Estados Unidos Mexicanos”, en Revista del Instituto de Salubridad y Enfermedades Tropicales, vol. 1, núm. 2, pp. 131-150. 
__ 1941, "Esperanza de vida en veinte estados mexicanos”, en Revista del Instituto de Salubridad y Enfermedades Tropicales, vol. 2, núm. 1, pp. 5-18.

Campiglia, Mercedes, 2017, La institucionalización del nacimiento. El vínculo roto, tesis de doctorado en antropología, Centro de Investigaciones y Estudios Superiores en Antropología Social, México.

Donovan, Jenny L. y David R. Blake, 1992, “Patient Non-Compliance: Deviance or Personal Decision-Making?”, en Social Science \& Medicine, vol. 34, núm. 5, pp. 507-513.

González, Antonio y Miguel A. Sandoval, 1946, "Acción de la penicilina sobre los hongos patógenos", en Revista del Instituto de Salubridad y Enfermedades Tropicales, vol. 7, núm. 4, pp. 193-200.

Kroeger, Alexis, Manuel Mancheno, Wilson Ruiz y Eduardo Estrella (comps.), 1991, Malaria y leishmaniasis cutánea en Ecuador. Un estudio interdisciplinario, Museo Nacional de Medicina de la Universidad Central/Instituto de Higiene Tropical de la Universidad de Heidelberg, Quito.

Kronman, Matthew, Chuan Zhou y Rita Mangione-Smith, 2014, "Bacterial Prevalence and Antimicrobial Prescribing Trends for Acute Respiratory Tract”, en Pediatrics, vol. 134, núm. 4, pp. e956-e965.

Litman, Theodor J., 1974, "The Family as a Basic Unit in Health and Medical Care: A Social-Behavioral Overview", en Social Science \& Medicine, vol. 8, núms. 9-10, pp. 495-519.

McKeown, Thomas, 1976, The Modern Rise of Population, Academic Press, Nueva York.

Menéndez, Eduardo L. (ed.), 1982a, Medios de comunicación masiva, reproducción familiar y formas de medicina popular, Centro de Investigaciones y Estudios Superiores en Antropología Social (Cuadernos de la Casa Chata 57), México.

-, 1982b, "Automedicación, reproducción social y terapéutica y medios de comunicación masiva”, en Eduardo L. Menéndez (ed.), Medios de comunicación masiva, reproducción familiar y formas de medicina popular. Centro de Investigaciones y Estudios Superiores en Antropología Social (Cuadernos de la Casa Chata 57), México, pp. 4-51.

, 1983, Hacia una práctica médica alternativa. Hegemonía y autoatención (gestión) en salud, Centro de Investigaciones y Estudios Superiores en Antropología Social (Cuadernos de la Casa Chata 86), México.

1984, "El modelo médico hegemónico: transacciones y alternativas hacia una fundamentación teórica del modelo de autoatención en salud", en Arxiu d'Etnografia de Catalunya, núm. 3, pp. 82-119.

—_, 1992, "Grupo doméstico y proceso de salud/enfermedad/atención. Del 'teoricismo' al movimiento continuo", en Cuadernos Médico Sociales, núm. 59, pp. 3-18.

__ , 1994, “La enfermedad y la curación. ¿Qué es medicina tradicional?”, en Alteridades, vol. 4, núm. 7, pp. 71-83.

2009, De sujetos, saberes y estructuras. Introducción al enfoque relacional en el estudio de la salud colectiva, Lugar Editorial, Buenos Aires.

Ortega, Judith y Judzil Palma, 2017, “Comunicación, género y autoatención: acción social en prevención de cánceres”, en Judith Ortega Canto y José Pérez Mutul (coords.), Cánceres en mujeres mayas de Yucatán. Pobreza, género y comunicación social, Universidad Autónoma de Yucatán/Plaza y Valdés, México, pp. 199-244.

Pinker, Steve, 2012, Los ángeles que llevamos dentro: el declive de la violencia y sus implicaciones, Paidós, Barcelona.

Populations Reports, 1981, "La terapia de rehidratación oral (TROP) en el tratamiento de la diarrea infantil”, en Populations Reports, serie L, núm. 2.

Wuthnow, Robert, 1996, Actos de compasión, Alianza, Madrid. 